\title{
nature
}

\section{In defence of DARPA}

The Pentagon's boldest research agency is in trouble; its unique character is in real danger. DARPA's officials and those who have benefited from its largesse must engage in open debate about the agency's value.

f you plan to visit the US Defense Advanced Research Projects Agency (DARPA), be sure to take a map. The agency resides in a nondescript, black-panelled building in a Washington suburb; its only distinguishing feature is a police car parked in front of the main entrance 24 hours a day.

Like the building it calls home, DARPA can be aptly described as a black box. Its funding decisions are determined not by peer review, but by the whims of programme managers, usually seconded from academia or industry. Their sole guidance is DARPA's mission of backing imaginative, creative and high-risk research in the interest of the defence of the United States. Scientists who capture the imagination of a programme manager can gain support for projects that would be dismissed by other agencies as too speculative to win public funding.

This freewheeling approach has yielded some big payoffs, such as the radar-absorbing skin of 'stealth' aircraft, and a host of critical Internet technologies. Today, the agency is pioneering the development of spintronics and quantum computing, which together could transform information technology. It has also extended its innovative reach into systems neuroscience, and other areas of biology.

But DARPA's capricious funding methods have led it down some strange roads. In the early 1970s, the agency dispatched a team to test the psychic prowess of spoon-bender Uri Geller. More recently, DARPA devoted hundreds of thousands of dollars to disputed research into tabletop nuclear 'bubble fusion'.

But earlier controversies are nothing compared with the storm whipped up by DARPA's Information Awareness Office. Created to investigate new intelligence-gathering techniques in the wake of the terrorist attacks of 11 September 2001, the office was headed by John Poindexter - who, as President Reagan's national security adviser in the 1980s, was a central figure in the Iran-Contra scandal.
Poindexter's office has trampled close to cultural taboos, especially civil liberties - an early programme to monitor financial records for terrorist activity contained disturbing echoes of 'Big Brother'. Now a study that sought to predict threats by asking investors to bet on a 'futures market' in terrorism, known as FutureMAP, has triggered an intense storm. Poindexter has tendered his resignation, and DARPA's congressional overseers are on the warpath (see page 601).

By its very nature, DARPA funds projects that critics will be able to depict as absurd or sinister. If the agency is to hold up under the scrutiny that it can now expect, it must overhaul its 'black box' image. Historically, DARPA has given little thought to public and media relations - and recent actions have shown it to be naive in this sphere. At the height of the terrorist-futures controversy, the project's web page disappeared, and this year a misguided Information Awareness Office logo sporting an unblinking eye staring down on the world was similarly axed. Neither really disappeared: privacy groups quickly posted the vanished pages on their own websites; G-strings and coffee mugs sporting the old logo can be purchased online. In the end, these moves only made DARPA look like it had something to hide.

Rather than trying to sweep its mistakes under the carpet, DARPA should be open and clear about the research it funds. It must engage in public debate about its more controversial work, and explain why pushing back the boundaries of our understanding requires occasional forays into areas that sound absurd or ethically questionable.

Meanwhile, scientists who have benefited from DARPA's unique approach should remind politicians and the public of what would be lost were the agency to be reined in. DARPA has existed since 1958 as a one-of-a-kind research organization. It is unlikely to disappear. But if its supporters fail to speak out, the ingenuity that distinguishes DARPA from the pack very well could.

\section{Hubble versus the future}

\section{NASA's science managers should be cut some financial slack to prevent the sacrifice of a prized research asset.}

W hat could be sillier than throwing away the Hubble Space Telescope, one of the most productive instruments in the history of science? That was the message from most speakers at last week's public meeting on the telescope's fate (see page 603). Yet there was dissent, mostly from people whose projects face delays if Hubble gains an extended life beyond its planned demise in 2010.

Foremost among those projects is the James Webb Space Telescope (JWST). Despite being conceived as the Next Generation Space Telescope, it is not Hubble's successor. It will observe in the near- and midinfrared, where Hubble is not so competitive. In a decadal review of priorities published in 2000, US astronomers asked for a large infrared space telescope, not for Hubble 2 - and that's just what NASA is giving them. But circumstances have changed. The JWST was due to launch in 2007, but now will not arrive until 2011 at the earliest. Nervous astronomers have come to see the value of a bird in the hand.

At last week's meeting, Bruce McCandless, a former astronaut who helped to place Hubble in orbit in 1990, suggested that major instruments should not be decommissioned until user demand drops. Other satellites, such as the International Ultraviolet Explorer and the Compton Gamma Ray Observatory, were arguably past their prime when they were shut down. But observing time on Hubble looks set to remain as coveted as ever for many years to come.

Unfortunately, NASA can't pay for the JWST and other future projects without retiring Hubble, unless Congress and the White House decide to loosen the purse strings. NASA's science managers have already been rewarded with budget increases for their relative financial rectitude, while those in charge of the space station have been punished for their profligacy. Astronomers can make a strong case for further cash injections into NASA's science programme, to delay Hubble's demise without sacrificing the JWST's timetable.

In today's harsh economic climate, there's no guarantee of success. But that shouldn't stop NASA earmarking small sums for preliminary studies of future Hubble instruments, to preserve the option of upgrading the telescope again after 2005 if the cash is forthcoming. 